\title{
The Correlation of Online Social Cognitive Capital Towards Knowledge Transfer Consumer Willingness to Pay: A Case Study
}

\author{
Jianyu Zhu ${ }^{1, *}$, Ruiqi Zhu ${ }^{2}$, Zunkai Weng ${ }^{3}$ \\ ${ }^{1}$ Jiaxiang Foreign Language School, Chengdu, 610000, China, \\ ${ }^{2}$ Ulink College of Suzhou Industrial Park, Suzhou, 215000, China \\ ${ }^{3}$ Sendelta International Academic, Shenzhen, 510810, China \\ *Jianyu_zhu@outlook.com
}

\begin{abstract}
The research towards the consumer willingness to pay in the knowledge sharing economy has begun for decades. Related research has shown that the social cognitive capital, or the expected gain of consumer, has a significant correlation towards knowledge exchange consumer willingness to pay. But for there is a difference between knowledge transfer and knowledge exchange, the acquisition and application of knowledge by the consumer. Whether the correlation is same? We use Python and analysis Tencent Classroom, a knowledge payment platform, as a case. But in the major striped sub-marketplace, there is only a moderate correlation between the social cognitive capital and consumer willingness.
\end{abstract}

Keywords: Knowledge Transfer, Social Capital, Consumer Willingness to Pay.

\section{INTRODUCTION}

\subsection{Purpose of the Research}

The conception of knowledge transfer through elearning platforms is not something new; universities have been using the e-learning platform to deliver literature for students to expand scope, content quality and diversity in the curriculum for decades [1]. The rapid development of Internet technology makes it possible for ordinary people to access information resource. Simultaneously, the rapid growth of the internet also drives down the cost of information and the external cost for acquiring, storing, transiting and sharing of information [2]. The knowledge is also a source of information. The knowledge sharing processes are mostly free rather than paid before the advent of sharing economy, which means that the payment in knowledge sharing symbolised the emergence of the knowledge sharing economy [3].

So, what affects the payment inside the knowledge sharing economy? There is already research towards the willingness to pay in the field of knowledge exchange (payment), indicating that online cognitive social capital imposes a significant positive influence on the consumer in knowledge exchange [4]. Despite the proof of such correlation in knowledge exchange (payment), is this still valid in knowledge transfer? Thus, this paper takes "Tencent Classroom" as a case to research whether this correlation is still effective towards willingness to pay among knowledge transfer consumers.

\subsection{Case of the Research}

Tencent Classroom is an e-learning platform that offers both live and pre-recorded courses. Launched by Tencent Ltd., one of the largest Internet oligopolists in China, in April 2014, it holds around 7 million active users until January 2021. Tencent Courses cover a wide range of courses topics, including IT Training, Arts and Design Training, E-commerce Operational Training, Vocational Training, Hobbies and Interests Training, Languages Training and After-School Training (Colleges, Secondary Schools and Primary Schools). The knowledge provider on Tencent Classroom could be whether education institution or individual teachers. And Tencent Classroom offers both free and paid courses for the consumers.

On the separate pages of each topic, the platform provides a list of related courses. The consumer can select more detailed sub-topics and pay or not, then rank the list by the rate of positive feedbacks, popularity and 
price. Some brief information about courses, such as the course and provider's name, price, and sales, are available on the topic pages. While on the pages for each course, consumers can see more detailed information, like courses time, the introduction of courses, content and index overview, commentary feedback, and positive feedback rate (towards the target course and the provider).

Tencent Classroom trend to be a knowledge transfer platform for the typical courses involves knowledge sharing (training by the knowledge provider), knowledge-seeking (searching and subscribing by the knowledge receiver) together with knowledge acquisition and application (practice and homework delivered by the knowledge provider).

\section{LITERATURE REVIEW}

\subsection{The concept of knowledge transfer}

As the Internet offers to convince on searching, people's demand towards answers and knowledge rises rapidly on the Internet. Like other types of sharing economies, the knowledge sharing economy is the largescale social shift towards knowledge originating from the Internet's invention [5]. In the knowledge sharing economy, the knowledge flows are considered the commodity that can be purchased or sold [6]. And the process of collection or creation, distribution and integration of knowledge is called knowledge flow [7]. For example, the knowledge involves in the knowledge flow is "idle" knowledge, experiences and skills [8].

There are three main concepts in the knowledge sharing economy, knowledge sharing, knowledge exchange and knowledge transfer. When the knowledge provider shares the knowledge flow or information to help or cooperate with others solving problems, this process is referred to as knowledge sharing [9]. In comparison, knowledge exchange is more bilateral than knowledge sharing. For the knowledge provider, it is similar to knowledge sharing. But the knowledge exchange involves knowledge-seeking, which means the process of knowledge receiver search and seek the knowledge from others [10]. Thus, knowledge payment is more similar to knowledge exchange, despite the fact that it holds some character of e-commerce [11]. As for knowledge transfer, it holds all the character of knowledge exchange. Additionally, the knowledge transfer requires the knowledge receiver to merge and apply the knowledge [8].

Typically, knowledge transfer facilitated through online platforms has a certain degree of e-learning. Electronic learning, or E-learning, is the learning promoted by electronic means [12]. The process of knowledge receiver acquisition and apply the knowledge is similar to the process of learning. If such a process bases on online platforms or remote learning software, it is true to say that in such circumstance, knowledge transfer is a means or form of e-learning.

\subsection{The Concept of Online Recognitive Social Capital}

Before the emergence of the Internet, the concept of social capital already existed. In the early 20th century, the general viewpoint towards social capital is that the accumulation of credit, friendship and other forms of social interaction are the main social capital compositions [13]. Not until the late 20th century, the arguments of social capital focus on the field of sociology rather than the economy. Then the definition is pushed forward in the early 21 st century; the sum of resources is the social capital when an individual or a social unit owns existing and potential resources among a specific social relationship network [14].

The Internet era delivers the research of classification social capital. Two dimensions, online or offline, structural or cognitive, further classifies the social capital [15]. The objective social network structure like organisations or the group of social relationship is the structural social capital, and it is related to the numbers of member among the social structure [16]. So, on an online platform, the online structured social capital could refer to the numbers of followers. The cognitive social is the expected positive gains from the social relations and engagements, such as beliefs, perceptions and value [17]. Therefore, the positive feedbacks towards an object in a specific platform is an example of online social cognitive capital.

\section{RESEARCH MODEL}

In 2018, previous research have illustrated the significant correlation between consumer willingness to pay and the numbers of cognitive social capital in a knowledge exchange marketplace, Zhihu-live [18]. They regarded the numbers of participants as the indicator of willingness to pay. The model of research towards the knowledge transfer platform would be in a similar approach. The numbers of positive feedbacks towards each course on Tencent Classroom would be the online cognitive social capital, which is the independent variable in our model. Simultaneously, the Tencent Classroom also offers a positive feedback rate of the knowledge sharers to give out the historical expected value of courses delivery. Therefore, this model will also involve the historical positive feedback rate of knowledge sharers as the another means online cognitive social capital. 


\section{Online Cognitive Social Capital}

\section{Consumer Willingness to Pay}

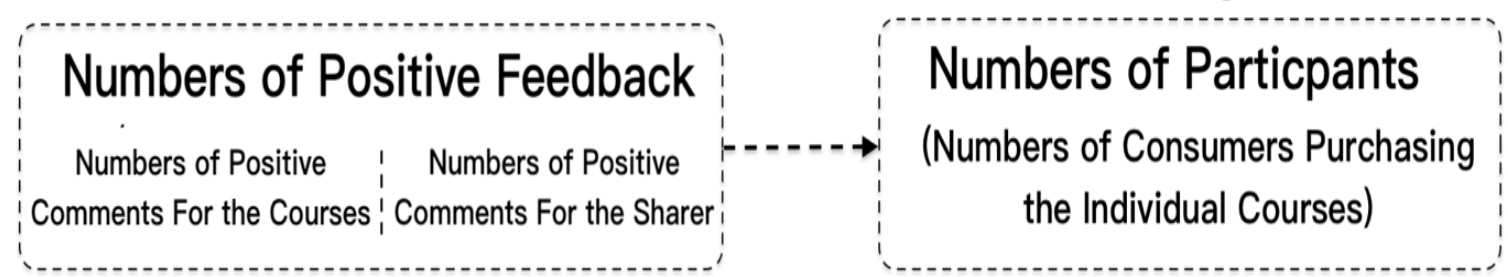

Figure 1 Research Model

At the same time, the numbers of sales on the Tencent Classroom would be considered as a factor of the consumer willingness to pay, which is the dependent variable.

But due to the web structure of Tencent Classroom, it could not be considered as a single marketplace. Because the consumer enters the platform, and they will select the specific kind of courses and seek their desired target in the given list. To a certain degree, there is independence between each section of Tencent Classroom with different consumer profile. This is due to the fact that knowledge-seeking, one main character of knowledge exchange and knowledge transfer, creates different profiles of seekers for distinguished demand. Therefore, the model and analysis for the whole platform will stripe into seven catalogues, which is the same for the aspect of courses Tencent involves. (IT Training, Arts and Design Training, E-commerce Operational Training, Vocational Training, Hobbies and Interests Training, Languages Training and After-School Training)

\section{RESEARCH METHOD}

\subsection{Data Collection and Processing}

The data collection process in the study involves using python to scrape (selenium) data from the Tencent Classroom. In total, the crawler obtains a set that involves 6976 raw data from the paid courses in Tencent Classroom. To select eligible data, we remove the courses with zero sales or zero online social capital. Also, we divide the data due to its different catalogues in order to avoid the impact of separated sections on Tencent Classroom. In order to make a comparison with the online cognitive social capital, we also get the data of the price for each course. Then, we deploy NumPY, a statics library for python, to calculate the Pearson Correlation among the price or online cognitive social capital with the sales number of each course or factor's effect on consumer willingness to pay.

\subsection{Data Illustration}

The results of the Pearson Correlation Coefficient among Price-Sales, Price-Online Cognitive Social Capital (Course \& Sharer) are shown in the Table 1

Table 1 Data Illustration

\begin{tabular}{|l|l|l|l|l|}
\hline & $\begin{array}{l}\text { Selected Data } \\
\text { Number }\end{array}$ & $\begin{array}{l}\text { Price-Sales } \\
\text { PMCC }\end{array}$ & $\begin{array}{l}\text { Online Cognitive } \\
\text { Social Capital } \\
\text { (Course)-Sales } \\
\text { PMCC }\end{array}$ & $\begin{array}{l}\text { Online Cognitive } \\
\text { Social Capital } \\
\text { (Sharer)-Sales } \\
\text { PMCC }\end{array}$ \\
\hline IT & 1452 & -0.01563 & 0.06393 & 0.00272 \\
\hline Design & 831 & 0.00815 & 0.311581 & 0.04007 \\
\hline Ecommerce & 493 & 0.002470 & 0.03637 & 0.00259 \\
\hline Occupation & 490 & 0.11532 & 0.21298 & 0.06916 \\
\hline Further Education & 341 & -0.01903 & 0.35498 & 0.07674 \\
\hline Interest & 552 & -0.01414 & 0.28706 & 0.04440 \\
\hline Language & 152 & -0.00298 & 0.07283 & -0.12699 \\
\hline & & & & \\
\hline Overall & 4321 & -0.01428 & 0.06357 & 0.02122 \\
\hline
\end{tabular}




\subsection{Correlation Analysis}

The output of the data in 4.2 shows that the degree of the correlation on online cognitive social capital of the courses is higher than the other two. Among the section of Design, Ecommerce, and Further Education, there is a moderate correlation between the Online Cognitive Social Capital (Courses) and the numbers of Sales. And the degree of correlation between Online Cognitive Social Capital (Courses) and the numbers of Sales is close to moderate. As for the Occupation section, there is a small correlation. But there is no significant correlation in the IT and Language Parts.

Simultaneously, in major aspect, the social cognitive capital of the knowledge sharer has no significant correlation with the numbers of sales, despite there is a small correlation in the section of language. Similarly, the price only makes a small correlation towards numbers of sales in the part of Occupation. And the rest of the Sections, there is also no significant correlation.

In the overall analysis of the platform, none of the price, the online cognitive social capital of the courses and sharers has a significant correlation as well. Generally speaking, the degree of correlation of online social capital of the courses is the highest among that of price and online social recognitive capital of the knowledge sharers.

\section{CONCLUSION}

\subsection{Research Conclusion}

Through our analysis, the degree of correlation between the sales or consumer willingness to pay and courses' cognitive social capital could be more moderate in the knowledge transfer platform than that in knowledge exchange. This is different to the significant correlation in the knowledge exchange platform.

\subsection{Possible Explanation of the Conclusion}

One possible explanation of this moderate rather than significant correlation is the different platform pattern between knowledge exchange and knowledge transfer. One viewpoint for the positive correlation in the knowledge exchange is that high-quality interaction creates higher cognitive social capital in the online community [19]. But essentially, the platform pattern of knowledge transfer, which is the community, could be distinguished from the knowledge transfer. Rather than a community, knowledge transfer owns a certain degree of environments like learning interaction between an expert, or so-called teacher, and knowledge receiver or students [20]. And such interaction will not limit to the knowledge transfer platform. Simultaneously, there is also a positive relationship between online interaction in knowledge transfer learning platform and offline social capital [21] This means part of the online social capital transforms into offline social capital. On Tencent Classroom, typical ways for knowledge receiver to communicate with the sharer and other receivers are through other communicative social networking apps like Wechat or QQ. The knowledge receiver may show thanks to or interact with the knowledge sharers through offline or those non-platform path; this could reduce the online cognitive social capital, whether it is cognitive or structured.

\subsection{Limitation}

In this research, although a large amount of the data adds some statics significance to the research, the shortcomings cannot be ignored. Firstly, the division of the data could be not enough for the highly differentiated knowledge payment marketplace like Tencent Classroom. The seven general catalogues are still too large for such product differentiation. This is especially true for the section of the IT in Tencent Classroom; the IT section itself involves many sub contents like different languages or types of technology. And this is the reason the Pearson Correlation Coefficient shows there is merely no correlation between social cognitive capital and the willingness to pay. Secondly, for showing the degree of online cognitive capital has a more moderate correlation towards willingness to pay, our research takes into the price to make a comparison. Therefore, the free courses on Tencent Classroom are ignored, but it is also a part of knowledge transfer if it satisfied the knowledge transfer definition. Thirdly, for the limitation of the data provided directly on the Tencent Classroom, we assume that the sales could be a factor reflecting consumer willingness to pay. But it is not clear that whether such an assumption is accurate. Thus, our future research has a large way to go for the limitation above.

\section{REFERENCES}

[1] Foster, L., 2001. Technology: Transforming The Landscape of Higher Education. The Review of Higher Education, 25(1), pp.115-124.

[2] Grewal, D., Iyer, G., Krishnan, R. and Sharma, A., 2003. The Internet and the price-value-loyalty chain. Journal of Business Research, 56(5), pp.391398.

[3] Song, J., Kim, H., Park, S. and Bae, S., 2014. Developing Knowledge Creating Technical Education Institutions through the Voice of Teachers: Content Analysis Approach. Career and Technical Education Research, 39(1), pp.79-99.

[4] Liu, Xinyan and Feng, Jun, 2018. Research on the Influencing Factors of the Willingness to Pay for 
Knowledge Consumers in the Knowledge Payment Platform. WHICEB 2018 Proceedings. pp. 58.

[5] Finley, K., 2013. Trust in the Sharing Economy: An Exploratory Study. MA Global Media and Communication. The University of Warwick.

[6] Cellary, W., 2010. Paid Content a Way to Electronic Knowledge-Based Economy. Advances in Databases and Information Systems, pp.13-14.

[7] Cabrera, E. and Cabrera, A., 2005. Fostering knowledge sharing through people management practices. The International Journal of Human Resource Management, 16(5), pp.720-735.

[8] Qi, T., Wang, T., Ma, Y. and Zhou, X., 2019. Knowledge payment research: status quo and key issues. International Journal of Crowd Science, pp.117-137.

[9] Cummings, J., 2004. Work Groups, Structural Diversity, and Knowledge Sharing in a Global Organization. Management Science, 50(3), pp.352364.

[10] Wang, S. and Noe, R., 2010. Knowledge sharing: A review and directions for future research. Human Resource Management Review, 20(2), pp.115-131.

[11] Zhou, T., 2018. Understanding online knowledge community user continuance. Data Technologies and Applications, 52(3), pp.445-458.

[12] Kasraie, N. and Kasraie, E., 2010. Economies Of Elearning In The 21st Century. Contemporary Issues in Education Research (CIER), 3(10), pp.57.

[13] Hanifan, L. J., 1916. The Rural School Community Centre. Annals of the American Academy of Political and Social Sciences, 67, pp.130-138.

[14] Robert D. Putnam, 2000. Choice Reviews Online, 2000. Bowling alone: the collapse and revival of American community. 38(04), pp.38-2454-38-2454.

[15] Williams, D., 2006. On and Off the 'Net: Scales for Social Capital in an Online Era. Journal of Computer-Mediated Communication, 11(2), pp.593-628.

[16] Hofer, M. and Aubert, V., 2013. Perceived bridging and bonding social capital on Twitter: Differentiating between followers and followees. Computers in Human Behavior, 29(6), pp.2134-2142.

[17] Burton, P., "Andy" Wu, Y. and R. Prybutok, V., 2010. Social Network Position and Its Relationship to Performance of IT Professionals. Informing Science: The International Journal of an Emerging Transdiscipline, 13, pp.121-137.
[18] LIU, Y. and YANG, J., 2019. Research on Knowledge Payment Willingness and Its Influencing Factors. DEStech Transactions on Economics, Business and Management, (icem).

[19] Zhang, L. and Zhang, P., 2017. The Relationship Between Online/Offline Social Capital and User Behavior in Social Q\&A: the Case of Medical and Health Topics in Zhihu. Library and Information Service,

[20] Wilkesmann, M. and Wilkesmann, U., 2011. Knowledge transfer as interaction between experts and novices supported by technology. VINE, 41(2), pp.96-112.

[21] Kent, C., Rechavi, A. and Rafaeli, S., 2019. The Relationship Between Offline Social Capital and Online Learning Interactions. International Journal of Communication, (13), pp.1186-1211. 